\title{
Teen Vaping of E-Cigarettes has Gained Enough Popularity in CA Among Youth That Gov. Gavin Newsome Declared A Public Health Emergency
}

\author{
Sara Ellen Amster* \\ College of Professional Studies, USA
}

*Corresponding author: Sara Ellen Amster, College of Professional Studies, USA.

Received Date: : September 28, 2019

Published Date: October 31, 2019

\section{Short Communication}

Yet the public awareness campaign by the state health department also has seemed like too little too late. Newsome's critics charge he could have done more to keep kids safer from vaping tobacco and marijuana.

The same criticism has raged in MA, which took all vaping products off the market for four months, while nationally 3.6 million kids under 18 are vaping, NBC news reported. The CDC found e-cigarette use by young people has jumped 78 percent.

You might blame adults whose industries profit from the ignorance of kids and some parents. Education theorist Erik Eriksen defined adolescence as a time of great experimentation during which all things seem possible and feasible so he considered this life stage as filled with peril and possibility but very dangerous and challenging to the tenets of the adult world in which teenagers must function.

The latest reports about vaping have convinced me of what I have always known about cigarettes since my mother started smoking as a young teacher. I used to grab her pocketbook, steal the cigarettes and break them in half joyfully to flush them down the toilet.

To teenagers, adults, namely school officials, teachers and public officials, can seem stuffy, overly cautious and protective of them. Adults are trying to make the world safer or "child proof" the teens' environment despite the fact that nowhere is 100 percent safe, the teens might counter.

Certain aspects of marijuana could be deemed healthful for treating particular disorders like M.S., and some cigarette brands are actually permitted to call themselves. "naturals." Yet it is hard to believe inhaling any kind of smoke is as safe as taking in air. Lots of poisons also are found in nature.

This is why guiding a teen through this stage of life is no simple task. Young people are in a time when they feel invincible --like they can do everything adults can - even though they really cannot. In many places and at many points in history teens literally were considered the same as adults by law. No longer tadpoles, they coveted the freedom of adopting adult behavior.

Now the question of what products are healthy for them to use has taken on greater significance where I live in southern CA as the state legalized marijuana for anyone over 21 so there is an increase of teens privately vaping both marijuana and tobacco.

Students vape between classes and use bathroom stalls to hide their practices. It is hard to detect because e-cigarettes are smokeless and leave less mess behind without any tell-tale stench.

My acts as a young girl to protect my mother's health were positive acts as now enough time has passed that I can say my hijinks actually lengthened her life and saved her to spend her old age out here in California where we both now reside.

During her 60s my mother, who turned 84 on Aug. 20, 2019 still had a bout with breast cancer and the smoking of her younger years may have been a factor in the endometrial cancer she developed and beat.

The popularity of "vaping" among teenagers has hit me hard as both an academic and the mother of two teen boys, one who is a vegetarian and very health conscious and the other who is much more tolerant of experimentation. He is out of the house now at the age of 19 and we no longer talk. 
Still, the national stories about "vaping" have hit my family hard The act is so popular that you find the streets littered with rolling paper from homemade marijuana cigarettes or blunts. Vaping and "healthier" e-cigarettes have become the new form of tobacco use here, exacerbating and informing this public health debate in my area of southern California. The medical science has not caught up to its popularity as a form of "alternative health" but I have always thought any kind of smoking is bad for you. I think that extends to smoking weed or grass or anything else because as I have told my sons, the only thing that belongs in their lungs is air.

I am an academic now - not a strong-willed 6-year-old ready to destroy all cigarettes that crossed my path, but I still know that the only substance needing to be in our lungs is oxygen. It is common sense that breathing in smoke is not healthy.

The green stuff or marijuana is as readily available as water and just as cheap and it is being legally sold over the counter as CBD oil that will not harm anyone and offers health benefits galore. As a mother, I remain doubtful about pot.

Still, it may not matter. There are legions of young workers who will deliver these drugs discreetly like pizza no matter where they are.
Vaping has resulted in a public health crisis that is not surprising to the 6-year-old self still inside of me.

I had thought baby powder was safe, This is because big drug companies enjoy immense power over the powder rooms women and moms running households for years, but now seem almost as bad as the tobacco industry and perhaps just as threatening to our lungs and those of our children. I do remember times when my bathroom was so filled with powder it made me cough.

Thus, I urge you gentle readers to work harder at curbing the popularity of "vape" products that are reaching the tender hands of the most vulnerable people there are -- my kids are no longer babies, but they still need our protection.

\section{Acknowledgment}

None.

\section{Conflict of Interest}

Author declare no conflict of interest. 